\title{
Ocorrência de Neobenedenia melleni (Monogenea; Capsalidae) em Trichiurus lepturus (Perciformes; Trichiuridae), naturalmente infestados, no litoral do Rio de Janeiro, Brasil
}

\author{
Occurrence of Neobenedenia melleni (Monogenea: Capsalidae) in Trichiurus lepturus
} (Perciformes: Trichiuridae), naturally infested off coastal zone of Rio de Janeiro, Brazil

\author{
Adriano R. Carvalho ${ }^{1 ; 2}$; José L. Luque ${ }^{3 *}$ \\ ${ }^{1}$ Curso de Pós-Graduação em Ciências Veterinárias, Universidade Federal Rural do Rio de Janeiro - UFRRJ \\ ${ }^{2}$ Laboratório de Ecologia e Taxonomia de Helmintos, Universidade Federal de Juiz de Fora - UFJF \\ ${ }^{3}$ Departamento de Parasitologia Animal, Universidade Federal Rural do Rio de Janeiro - UFRRJ, \\ Bolsista de produtividade de Pesquisa do CNPq \\ Recebido em 11 de Setembro de 2008 \\ Aceito em 19 de Agosto de 2009
}

\section{Resumo}

Neobenedenia melleni (MacCallum, 1927) é um conhecido patógeno de teleósteos confinados que exibe baixo grau de especificidade ao hospedeiro. Entre julho de 2006 a junho de 2007, 120 espécimes de Trichiurus lepturus Linnaeus, 1.758 foram adquiridos de pescadores locais na Baia de Guanabara (22 $57^{\prime} \mathrm{S}$ e $\left.42^{\circ} 41^{\prime} \mathrm{O}\right)$, Estado do Rio de Janeiro, Brasil, para o estudo da sua parasitofauna. A superfície do corpo foi raspada e os monogenéticos obtidos foram identificados como $N$. melleni, que apresentaram prevalência de 8,3\% e intensidade média de infecção 1,2 $\pm 0,42$. O presente trabalho teve como objetivo fazer o primeiro registro de $N$. melleni parasitando hospedeiro silvestre na costa brasileira, aumentando, dessa forma, a distribuição geográfica conhecida dessa espécie de parasito.

Palavras-chave: Neobenedenia melleni, Trichiurus lepturus, monogenéticos, Brasil.

\begin{abstract}
Neobenedenia melleni (MacCallum, 1927) is a widely spread pathogen in teleost maricultures with a very low host specificity. Between July of 2006 to June of 2007, 120 specimens of Trichiurus lepturus Linnaeus, 1758 were acquired of local fishermen in the Guanabara Bay (22 $57^{\prime} \mathrm{S}$ and $\left.42^{\circ} 41^{\prime} \mathrm{W}\right)$, State of Rio de Janeiro, Brazil, to the study of the parasite fauna. The surface of the host body was scraped and the monogeneans obtained were identified as N. melleni, which showed prevalence of $8.3 \%$ and mean intensity of infection $1.2 \pm 0.42$. Data about morphology of the specimens collected were included herein. Neobenedenia melleni is recorded by the first time parasitizing on a wild host from the Brazilian coastal zone.
\end{abstract}

Keywords: Neobenedenia melleni, Trichiurus lepturus, monogeneans, Brazil.

Neobenedenia melleni (MacCallum, 1927) é um conhecido patógeno de teleósteos confinados que exibe baixo grau de especificidade ao hospedeiro (BULLARD et al., 2003). Há registros de mais de 100 espécies de peixes teleósteos, pertencentes a mais de 30 famílias, de cinco ordens com registro de parasitismo por N. melleni (WHITTINGTON, 2004). Dados sobre a distribuição geográfica de $N$. melleni, em peixes naturalmente infestados, são escassos e abrangem a costa leste da América do Norte, Mar do Caribe, Golfo do México e Chile (WHITTINGTON; HORTON, 1996; BULLARD et al., 2000; 2003; OLIVA; GONZALEZ, 2004). Quando considerados os registros de epidemias de $N$. melleni em

\footnotetext{
*Autor para correspondência: José L. Luque

Departamento de Parasitologia Animal,

Universidade Federal Rural do Rio de Janeiro - UFRRJ

Rodovia BR - 465, Km 7, CP 74.508, CEP 23.890-000 Seropédica - RJ, Brasil e-mail: jlluque@ufrrj.br
}

peixes de cultivo, sua distribuição se estende do oeste do oceano Pacífico ao Havaí, Bali, costa oeste da Austrália, Mar Vermelho, Malásia e Indonésia (KANEKO et al., 1988; COLORNI, 1994; LEONG, 1997; KOESHARYANI et al., 1999; DEVENEY et al., 2001; RÜCKERT et al., 2008).

Nos peixes de aquários e outros tipos de sistemas de criação com recirculaçáo da água do mar, como caixas suspensas, foram registradas altas intensidades de infestaçâo por $N$. melleni, marcadas por lesôes com hemorragias, descoloração do corpo, emagrecimento e comportamento errático (JAHN; KUHN, 1932; NIGRELLI; BREDER, 1934; OGAWA et al., 1995; DEVENEY et al., 2001; BULLARD et al., 2003). Por outro lado, em hospedeiros silvestres, a intensidade de infestação é baixa, não existindo registro de doença e nem informaçōes detalhadas relacionadas a lesōes associadas com infestaçôes de N. melleni (BULLARD et al., 2003). 
Recentemente, N. melleni foi registrada em pisciculturas do Brasil, em criaçóes de garoupas Epinephelus marginatus, sendo sugeridas inclusive algumas medidas para o controle dessa parasitose (SANCHES; VIANNA, 2007; SANCHES, 2008). O presente trabalho teve como objetivo fazer o primeiro registro de $N$. melleni parasitando hospedeiro silvestre na costa brasileira, aumentando, dessa forma, a distribuição geográfica conhecida dessa espécie de parasito.

Entre julho de 2006 a junho de 2007, 120 espécimes de Trichiurus lepturus Linnaeus 1.758 foram adquiridos de pescadores locais na Baia de Guanabara $\left(21-23^{\circ} \mathrm{S}\right.$ e $\left.41-45^{\circ} \mathrm{W}\right)$, Estado do Rio de Janeiro, Brasil. A superfície do corpo foi raspada e o material observado em microscópio estereoscópio. Alguns espécimes foram corados com tricrômico de Gomori ou hematoxilina de Delafield, enquanto outros foram montados em meio de Gray e Wess, como descrito por Thatcher (2006). Desenhos foram feitos com a ajuda de tubo de desenho acoplado a microscópio Olympus BX-51 com contraste de fase. Medidas são fornecidas em micrômetros; a media é seguida pela amplitude e pelo número de espécimes medidos (n) entre parênteses. No presente trabalho, os parasitos foram identificados usando-se a descrição original de N. melleni (como Epibdella melleni MacCallum, 1927) e a redescrição e chave de identificação específica de $N$. melleni de Whittington e Horton (1996). A terminologia ecológica segue Bush et al. (1997). Espécimes testemunhos foram depositados na Coleção Helmintológica do Instituto Oswaldo Cruz (CHIOC), Rio de Janeiro, Brasil.

Neobenedenia melleni (MacCallum, 1927) (Capsalidae Baird, 1853)

Descrição: Corpo elipsoide. Comprimento total, incluindo o haptor, $3.875(2.575-6.450 \mu \mathrm{m}, \mathrm{n}=6)$, largura máxima ao nível dos testículos, $1.625(975-2.625 \mu \mathrm{m}, \mathrm{n}=6)$. Haptor circular, diâmetro $1.080(775-1.500 \mu \mathrm{m}, \mathrm{n}=6)$ comprimento, $1.109(800-1.700 \mu \mathrm{m}, \mathrm{n}=6)$ largura. Esclerito acessório $191(140-270 \mu \mathrm{m}, \mathrm{n}=6)$ comprimento, com fenda longitudinal e extremidade bífida. Âncora anterior $320(240$ - $450 \mu \mathrm{m}, \mathrm{n}=6)$ comprimento, robusta, recurvada em sua extremidade distal, com fenda longitudinal. Âncora posterior 115 (90 - $150 \mu \mathrm{m}, \mathrm{n}=6)$ comprimento, reta, com fino gancho na sua extremidade distal. Sete pares de ganchos distribuídos na margem do haptor, 10,6 (10 - 12,5 $\mu \mathrm{m}, \mathrm{n}=5)$. Órgãos de fixaçáo anteriores ovais, $246(170-300 \mu \mathrm{m}, \mathrm{n}=5)$ comprimento, $341(210-470 \mu \mathrm{m}, \mathrm{n}=5)$ largura, não há divisão transversal separando as regióes anterior e posterior. Faringe $305(210-550 \mu \mathrm{m}, \mathrm{n}=6)$ comprimento, $351(260-500 \mu \mathrm{m}, \mathrm{n}=6$ ) largura. Cecos intestinais dendríticos. Testículos esféricos, com superfície levemente irregular $392(210-570 \mu \mathrm{m}, \mathrm{n}=6)$ comprimento, $263(160-350 \mu \mathrm{m})$ largura. Ovário oval $248(110-520 \mu \mathrm{m}, \mathrm{n}=6)$ comprimento, $225(120-450 \mu \mathrm{m}, \mathrm{n}=6)$ largura. Câmara intraovárica observada em alguns espécimes. Poro genital comum sinistral e ventral, abrindo-se na altura da faringe. Folículos vitelínicos, extendendo-se da região anterior da faringe até o final do corpo.

Hospedeiro: Trichiurus lepturus Linnaeus 1.758, Trichiuridae.

Local de infestação: superfície do corpo.

Localidade: Baia de Guanabara (22 $57^{\prime} \mathrm{S}$ e $\left.42^{\circ} 41^{\prime} \mathrm{O}\right)$, Rio de Janeiro, RJ, Brasil.
Prevalência: $8,3 \%$ (10 de 120 peixes examinados).

Intensidade média: $1,2 \pm 0,42$.

Espécimes testemunhos: Três espécimes corados e montados, CHIOC no 37232 a,b,c

Descriçóes de espécimes de $N$. melleni de hospedeiros diferentes são necessárias, uma vez que ocorre variação no tamanho dos espécimes, no formato do corpo e dos testículos, além do tamanho e formato dos escleritos (WHITTINGTON; HORTON, 1986), características que levaram alguns pesquisadores a acreditar que $N$. melleni constitui um grupo de espécies indiferenciáveis morfologicamente, o que explicaria a grande gama de hospedeiros parasitados (WHITTINGTON, 2004). Morfologicamente, as características específicas dos espécimes deste estudo foram consistentes com MacCallum (1927) e com Whittington e Horton (1996).

Estudos de hospedeiros silvestres naturalmente infestados são importantes para o conhecimento dos indicadores populacionais de N. melleni, registro de novos hospedeiros e novas áreas geográficas. Essa constatação, de acordo com Bullard et al. (2003), pode auxiliar no manejo e gerenciamento da aquicultura, prevenindo e controlando doenças associadas a infestaçóes de $N$. melleni. Os valores registrados de prevalência e intensidade do parasitismo de $N$. melleni, observadas na amostra de T. lepturus naturalmente infestados, foram baixas, semelhantes àqueles reportados por Bullard et al. (2003) e por Oliva e Gonzalez (2004) que também estudaram a infestação natural de $N$. melleni em amostras de peixes do Golfo do México e da costa chilena, respectivamente.

Bullard et al. (2003) mencionaram que o comportamento de formar cardumes facilitaria a dispersáo horizontal das larvas de monogenéticos em algumas espécies de peixes, no entanto, os indicadores populacionais de $N$. melleni apontam para o fato de que, no presente trabalho, tal comportamento, apresentado por T. lepturus, não influenciou a transmissão horizontal de N. melleni.

\section{Referências}

BULLARD, S. A. et al. Six new host records and an updated list of wild hosts for Neobenedenia melleni (MacCallum) (Monogenea: Capsalidae). Comparative Parasitology, v. 67, n. 2, p. 190-196, 2000.

BULLARD, S. A. et al. A new geographic locality and three new host records for Neobenedenia melleni (MacCallum) (Monogenea: Capsalidae). Gulf and Caribbean Research, v. 15, n. 1, p. 1-4, 2003.

BUSH, A. O. et al. Parasitology meets ecology on its own terms: Margolis et al. revisited. Journal of Parasitology, v. 83, n. 4, p. 575-583, 1997.

COLORNI, A. Hyperparasitism of Amyloodinium ocellatum (Dinoflagellida: Oodinidae) on Neobenedenia melleni (Monogenea: Capsalidae). Diseases of Aquatic Organisms, v. 19, n. 1, p. 157-159, 1994.

DEVENEY, M. R.; CHISHOLM, L. A.; WHITTINGTON, I. D. First published record of the pathogenic monogenean parasite Neobenedenia melleni (Capsalidae) from Australia. Diseases of Aquatic Organisms, v. 46, n. 1, p. 79-82, 2001.

JAHN, T. L.; KUHN, L. R. The life history of Epibdella melleni MacCallum, 1927, a monogenetic trematode parasitic on marine fishes. Biological Bulletin, v. 62, n. 1, p. 89-111, 1932. 
KANEKO, J. J. et al. Infection of tilapia, Oreochromis mossambicus (Trewavas), by a marine monogenean, Neobenedenia melleni (MacCallum, 1927) Yamaguti, 1963 in Kaneohe Bay, Hawaii, USA, and its treatment. Journal of Fish Diseases, v. 11, n. 4, p. 295-300, 1988.

KOESHARYANI, I. et al. Two species of capsalid monogeneans infecting cultured humpback grouper Cromileptes altivelis in Indonésia. Fish Pathology, v. 34, n. 3, p. 165-166, 1999.

LEONG, T. S. Control of parasites in cultured marine finfishes in southeast Ásia: an overview. International Journal for Parasitology, v. 27 , n. 10 , p. $1177-1184,1997$.

MacCALLUM, G. A. A new ectoparasitic trematode, Epibdella melleni, sp. nov. Zoopathologica, v. 1, n. 2, p. 191-300, 1927.

NIGRELLI, R. F.; BREDER, C. M. The susceptibility and immunity of certain marine fishes to Epibdella melleni, a monogenetic trematode. Journal of Parasitology, v. 20, n. 2, p. 259-269, 1934.

OGAWA, K. et al. Neobenedenia girellae (Hargis, 1955) Yamaguti, 1963 (Monogenea: Capsalidae) from cultured marine fishes of Japan. Journal of Parasitology, v. 81, n. 2, p. 223-227, 1995.

OLIVA, M. E.; GONZALEZ, M. T. Metazoan parasites of Sebastes capensis from two localities in northern Chile as tools for stock identification. Journal of Fish Biology, v. 64, n. 1, p. 170-175, 2004.
RÜCKERT, S.; PALM, H. W.; KLIMPEL, S. Parasite fauna of seabass (Lates calcarifer) under mariculture conditions in Lampung Bay, Indonésia. Journal of Applied Ichthyology, v. 24, n. 3, p. 321-327, 2008.

SANCHES, E. G. Controle de Neobenedenia melleni (MacCallum, 1927) (Monogenea: Capsalidae) em garoupa-verdadeira, Epinephelus marginatus (Lowe, 1834), cultivada em tanques-rede. Revista Brasileira de Parasitologia Veterinária, v. 17, n. 3, p. 145-149, 2008.

SANCHES, E. G.; VIANNA, R. T. Ocorrência de Neobenedenia melleni (Monogenea: Capsalidae) em garoupa-verdadeira, Epinephelus marginatus (Lowe, 1834), cultivada em tanques-rede. Arquivos de Ciências do Mar, v. 40, n. 2, p. 96-100, 2007.

THATCHER, V. E. Amazon Fish Parasites. 2 ed. Sofia-Moscow: Pensoft Publishers, 2006. 508 p.

WHitTingTON, I. D. The Capsalidae (Monogenea: Monopisthocotylea): a review of diversity, classification and phylogeny with a note about species complexes. Folia Parasitologica, v. 51, n. 2/3, p. 109-122, 2004.

WHITTINGTON, I. D.; HORTON, M. A. A revision of Neobenedenia Yamaguti, 1963 (Monogenea: Capsalidae) incluing a redescription of N. melleni (MacCallum, 1927) Yamaguti, 1963. Journal of Natural History, v. 30, n. 8, p. 1113-1156, 1996. 